\title{
Insecticides for public health
}

$\mathrm{P}$ aracelsus, the 16th-century Swiss physician, cottoned onto an important concept that has served humanity well: "The dose makes the poison." Most of us unknowingly accept this important observation as we drink our first cup of coffee in the morning or drink a beer at the end of the day. Coffee and beer, like many other foods and beverages, contain carcinogens, which, in sufficient quantity, would do us harm. As part of a balanced diet, however, their consumption is not harmful. What a pity that some members of the European Parliament and the European Commission are seemingly blind to a concept established over 400 years ago.

New European Union (EU) legislation to regulate the pesticides, fungicides and herbicides used in agriculture was approved in January and will come into effect in 2010. European commissioners and members of the European Parliament clearly want to make life safer for Europeans by attempting to rid their countries of any potentially harmful chemicals. Yet the legislation may well end up doing more harm than good by its effect on people living under very different circumstances than wealthy, healthy and well-fed Europeans.

Debate raged for several months in the EU and beyond about this critical change in the approach to regulating chemicals. Under early drafts of the legislation, risk assessments of chemicals were abandoned in favour of hazard-only assessments. The hazard approach is based on laboratory data, ignoring the real-world application of chemicals and the actual risk posed to humans and the environment (the essence of risk assessment). Under a hazard-based approach, the mere presence of a carcinogen or endocrine disruptor is sufficient to ban the chemical. It appears that the law will allow for some risk analysis, although there is still great uncertainty about how it will be implemented.

The law allows for products to be banned if they are found to be endocrine disruptors; however, there is no accepted

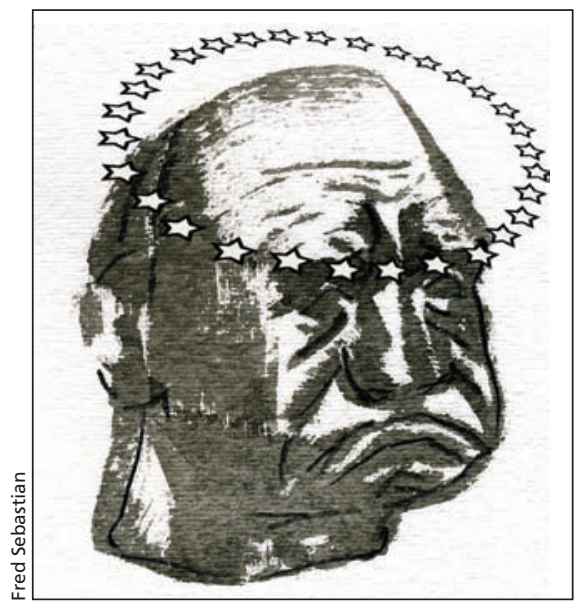

definition of endocrine disruption. A complex law such as this may suit legislators and lawyers, but it makes life difficult, uncertain and expensive for developers and manufacturers of chemicals, as well as for those who might use their products, most notably farmers.

No one really knows how farmers will be affected since a comprehensive impact assessment has never been done. A less acknowledged and potentially more disastrous effect of the new law will be on disease control in poor countries.

Controlling malaria and other insectborne diseases requires insecticides. When used for this purpose, the enormous benefit of reduced disease transmission far outweighs any risks insecticides pose. None of the insecticides used in disease control were created for this purpose; almost all were developed for agriculture. Once the use of these chemicals is banned, it will be financially unjustifiable to continue production for the tiny public health market. Even if some companies continue production, prices may be high and availability low.

Furthermore, even though insecticide resistance is a significant and growing problem in tropical disease control, these laws governing the production and use of insecticides will make it unlikely that investors will risk spending money on product research and development.

The new EU rules will most likely extend to imported produce, since it makes little sense to ban the use of chemicals at home only to import produce with residues of these same chemicals from countries still allowing their use. This may force farmers in Africa, North America and elsewhere to follow EU rules if they want to maintain these export markets. EU import restrictions already affect malaria control. Uganda and other countries have limited their use of insecticides in indoor spraying programs out of fear, and in the absence of any real evidence, that the tiniest residues of chemicals already banned in the EU would be found on produce. ${ }^{1}$ This new law could potentially lead to even less use of insecticides.

A more globalized world brings us all, rich and poor, many benefits from trade and free exchange. But there are downsides too. The EU was originally designed to ease the movement of goods, services and people. It has also ended up exporting an ill-conceived law that will harm people far and wide while bringing few benefits. Were Paracelsus alive today, he would no doubt be scratching his head.

\section{Richard Tren MSc \\ Director \\ Africa Fighting Malaria \\ Washington, DC}

\section{REFERENCE}

1. Uganda, President's malaria initiative - Uganda: Malaria operational plan for FY 2009. Final. Uganda: Government of Uganda; 2008. Available: www.fightingmalaria.gov/countries/mops/uganda _mop-fy09.pdf (accessed 2009 Mar. 4).

Africa Fighting Malaria is a nonprofit health advocacy group that aims to make malaria control more transparent, responsive and effective. Due to the nature of its work, it does not accept funding from governments, insecticide manufacturers or the pharmaceutical industry.

Have you got an opinion about this article? Post your views at www.cmaj.ca. Potential Salon contributors are welcome to send a query to salon@cmaj.ca. 